\title{
Low-income pre-schoolers with higher temperamental surgency enjoy and respond more to food, mediating the path to higher body mass index
}

\author{
C. Y. Y. Leung ${ }^{1}$, A. L. Miller ${ }^{1,2}$, N. A. Kaciroti ${ }^{1,3}$, Y. P. Chen ${ }^{1}$, K. Rosenblum ${ }^{1,4}$ and \\ J. C. Lumeng ${ }^{1,5,6}$
}

${ }^{1}$ Center for Human Growth and Development, University of Michigan, Ann Arbor, MI, USA; ${ }^{2}$ Department of Health Behavior and Health Education, School of Public Health, University of Michigan, Ann Arbor, MI, USA;

${ }^{3}$ Department of Biostatistics, School of Public Health, University of Michigan, Ann Arbor, MI, USA; ${ }^{4}$ Department of Psychiatry, University of Michigan, Ann Arbor, MI, USA; ${ }^{5}$ Department of Pediatrics and Communicable Diseases,

University of Michigan, Ann Arbor, MI, USA; ${ }^{6}$ Department of Environmental Health Sciences, School of Public Health, University of Michigan, Ann Arbor, MI, USA

Address for correspondence: Dr CYY Leung, Center for Human Growth and Development, University of Michigan, 300 North Ingalls Street, 10th Floor, Ann Arbor, MI 48109-5406, USA. E-mail: leungcyy@umich.edu

Received 1 December 2014; revised 22 April 2015; accepted 23 April 2015

\section{Summary}

Background: Temperament is associated with obesity risk. However, the mechanisms linking temperament and eating behaviour to childhood adiposity are unclear.

Objectives: To examine whether three temperament dimensions (surgency, effortful control and negative lability) are uniquely associated with an increased BMI z score (BMIz) concurrently and an excessive rate of change in BMlz longitudinally through four eating behaviours (food responsiveness, enjoyment of food, emotional overeating and satiety responsiveness) among low-income pre-schoolers, independent of home environment quality.

Methods: 379 pre-schoolers were recruited from Head Start in the Midwest region of the United States. Primary caregivers reported child temperament, eating behaviours and the level of chaos at home. Child BMlz was derived from weight and height measurements at ages 4, 5 and 6 years on average.

Results: Path analyses revealed that higher levels of surgency predicted more food responsiveness and enjoyment of food, which was in turn associated with higher concurrent BMIz, independent of effortful control, negative lability and home chaos.

Conclusion: Low-income surgent pre-schoolers were more likely to have elevated BMIz as they were more inclined to eat in response to external cues and have a high appetitive drive. Obesity prevention programmes might target lowincome children with surgent temperaments, and the identified eating behaviours.

Keywords: Eating behaviours, mediation, pre-schoolers, temperament. Abbreviations: BMlz, body mass index z score; $\mathrm{CBQ}$, Children's Behaviour Questionnaire; CFI, comparative fit index; HLM, hierarchical linear models; SRMR, standardized root mean residual

\section{Introduction}

Childhood obesity is common (1) and interventions are needed. Differences in temperament may explain why some young children are prone to obesity. Three temperament dimensions (surgency: high impulsivity, pleasure and novelty seeking, activity level; effortful control: ability to refrain from a behaviour, maintain attention, resist distraction; negativity: high lability, reactivity, negative emotion) (2) have been linked to risk of excess adiposity in children. Specifically, greater surgency (3), impulsivity (4), hyperactivity (4), poor inhibitory control $(5,6)$, limited ability to delay gratification (6,7), short attention span (8) and negative emotion $(4,5,9)$ have been associated with accelerated weight gain and/or higher weight status.

The mechanisms linking these temperament features to obesity risk are not entirely clear. Differences in eating behaviour such as external eating (10-12), frequent desire to eat $(12,13)$, emotional overeating $(11,12)$ and underresponsiveness to internal satiety cues (12) have been implicated in the development of childhood obesity. Findings from studies that have examined associations between temperament and obesity-promoting eating behaviour are not always in the expected direction. Specifically, children with lower inhibitory control are more vulnerable to external or emotional overeating (14-17). 
Contrary to what might be predicted, however, children with more negative affectivity are more responsive to satiety and less interested in eating $(18,19)$. We have previously examined associations between dimensions of temperament and children's eating behaviours (20), but whether these temperament features predict body mass index (BMI), and how those associations may be explained by the child's eating behaviours, remain unexamined.

Understanding the mechanisms linking temperament to elevated BMI is essential to developing effective interventions that can be tailored to children with the identified temperament characteristics. The present study sought to fill the following gaps in the present literature. First, no study has examined the mediating mechanisms linking these three temperament dimensions to adiposity through obesity-promoting eating behaviours. Second, children who experience early adiposity rebound (i.e. when BMl begins to increase from its nadir) have been reported to have an increased risk of obesity later in life $(21,22)$. Thus, pre-school is a critical developmental period for examining factors that may contribute to obesity-promoting eating behaviours and elevated BMI (23). Few studies have examined these associations in the pre-school age range $(7,14)$. Therefore, the present study tested the hypothesis that among pre-schoolers the temperament dimensions of higher surgency, lower effortful control and higher negative lability are each associated with greater adiposity and greater rates of increase in adiposity, and that these associations are mediated through greater obesity-promoting eating behaviours (food responsiveness, enjoyment of food, emotional overeating and satiety responsiveness). Furthermore, given that pre-schoolers have been shown to be more likely to engage in obesogenic eating or at greater risk for obesity when living in a chaotic home environment $(20,24)$, home environment quality (operationalized as level of chaos in the home) was considered as a covariate.

\section{Methods}

\section{Study design and participants}

Participants were pre-school-aged children from the Midwest region of the United States who were enrolled in a longitudinal study of child eating behaviour, with three assessments at ages 4, 5 and 6 years on average. Families were recruited from Head Start, a federally funded preschool programme for low-income children. Inclusion criteria were that the child was born at 35 weeks gestation or more and did not have any significant perinatal or neonatal complications, developmental disabilities, medical problems or food allergies; child was not in foster care; caregiver and child were English speaking; and caregiver did not have a college degree. Trained research assistants administered questionnaires orally to caregivers at the first time-point assessment. The study was approved by the University of Michigan Institutional Review Board. The current sample includes 379 participants with complete data for all variables in the analyses.

\section{Measures}

\section{Predictors: child temperament}

Children's primary caregivers completed the Children's Behaviour Questionnaire (CBQ) (2), on which they rated how well each item describes the child $(1=$ extremely untrue; $7=$ extremely true). The Surgency dimension is the mean of 25 items (e.g. 'often rushes into new situations'; $\alpha=.70$ ), capturing children's activity level, high-intensity pleasure, impulsivity and shyness (reversed). The Effortful Control dimension was measured using the mean of 12 items (e.g. "can easily stop an activity when she/he is told "no" '; $\alpha=.76$ ), capturing children's attention focusing and inhibitory control. Only the CBQ Surgency and Effortful Control scales were used due to time constraints. Caregivers also completed the 16-item Negative Lability scale of the Emotion Regulation Checklist (25). Items (e.g. 'is easily frustrated') were rated on a 1 (rarely/never) to 4 (almost a/ways) point scale and a mean was calculated $(\alpha=.85)$. On each of the scales, higher scores represent higher levels of the temperament dimension.

\section{Mediators: child eating behaviour}

Caregivers completed the Children's Eating Behaviour Questionnaire (14), a 35-item questionnaire to which caregivers responded on a scale of 1 (never) to 5 (always). Subscale scores are calculated as the mean of the contributing items, such that higher scores represent more of the given behaviour. Subscales included in this analysis were: food responsiveness assessing food consumption in response to external cues (e.g. 'my child is always asking for food'; five items; $\alpha=.84$ ); enjoyment of food capturing appetitive drive, desire to eat and interest in eating (e.g. 'my child loves food'; four items; $\alpha=.84$ ); emotional overeating reflecting a tendency to seek comfort through eating in response to emotional arousal (e.g. 'my child eats more when anxious'; four items; $\alpha=.79$ ); and satiety responsiveness referring to the ability to recognize internal satiety cues (e.g. 'my child gets full easily'; five items; $\alpha=.73$ ).

\section{Outcomes: concurrent BMI z score and rate of change in BMI z score}

Children were weighed and measured without shoes or heavy clothing by trained research assistants according to standard protocols using a $\pm 0.1 \mathrm{~kg}$ calibrated scale and a $\pm 0.1 \mathrm{~cm}$ calibrated stadiometer. Measurements were collected again an average of $0.7(S D=0.5)$ and 1.7 $(S D=0.5)$ years later. $\mathrm{BMI}$ was calculated and $\mathrm{BMI} z$ score (BMIz) derived using age- and sex-specific growth reference charts from the United States Centers for Disease Control and Prevention (26).

\section{Covariate: home environment quality}

Given reported associations of home environment quality with temperament (15), eating behaviours (15) and obesity (25), home environment quality was examined as a 
covariate. The Confusion, Hubbub, and Order Scale (27) was used to capture the extent to which the child's home environment is characterized by disorganization, confusion, noise and a lack of routine (i.e. chaos). Caregivers indicated whether each of the 15 items was true or false and following appropriate reverse coding. Items were summed $(\alpha=.80)$ such that higher scores represent greater home chaos.

\section{Statistical analysis}

Hierarchical linear models (HLM) (28) using random parameters were used to capture individual BMlz growth curves for each participant. This approach accounts for the time differential in the measurement of the BMlz in a direct way using the parametric function of the rate of change in BMlz per year. The random intercept is an estimate of the expected BMlz at the age of 4 years for a given individual, and the random slope is the expected rate of change in BMlz from 3 to 8 years of age.

Multivariate analyses accounting for intercorrelations among independent variables were implemented using path analyses to examine whether eating behaviours mediated the effect of child temperament on BMlz growth pattern (both intercept and slope), independent of home chaos. Four separate path models were run testing each of the four eating behaviours (food responsiveness, enjoyment of food, emotional overeating and satiety responsiveness), with the three temperament dimensions (surgency, effortful control and negative lability) and home chaos included (see Fig. 1). The covariance path between surgency and home chaos was non-significant and therefore excluded from the path analyses to obtain a more parsimonious model with a better fit. All analyses were conducted in IBM SPSS AMOS 21 (United States) using the maximum-likelihood estimation procedure. The nonparametric bootstrapping procedure was used for inferences on the indirect effects. The model fit was assessed based on the $\chi^{2}$ goodness-of-fit statistic being non-significant with a $P$-value $>.05$, comparative fit index $(\mathrm{CFI})>.90$ and standardized root mean residual $(\mathrm{SRMR})<.06(29)$.

\section{Results}

Demographic characteristics of the sample are presented in Table 1. Child mean age at the initial assessment was 4.2 years. Boys and girls were equally represented. Standardized path coefficients for the four model are presented in Fig. 1. All four models fit the data well, with $P$-values for the $\chi^{2}$ goodness-of-fit statistic ranging from .347 to .665, CFI ranging from .997 to 1.00, and SRMR ranging from .029 to .32 .

Food responsiveness significantly mediated the association between surgency and BMlz. Higher surgency was associated with more food responsiveness, $\beta=.14$. More food responsiveness in turn was associated with higher BMlz, $\beta=.21$. The indirect effect of surgency on BMlz through food responsiveness was significant. Food (a)

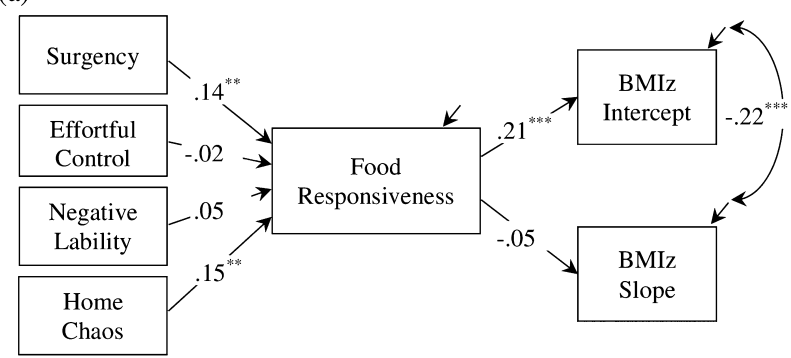

(b)

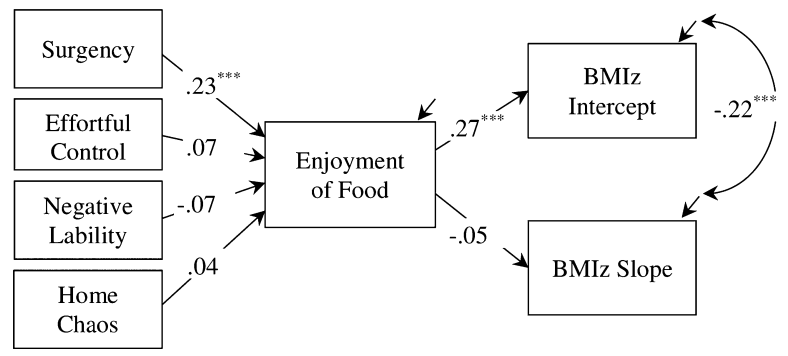

(d)

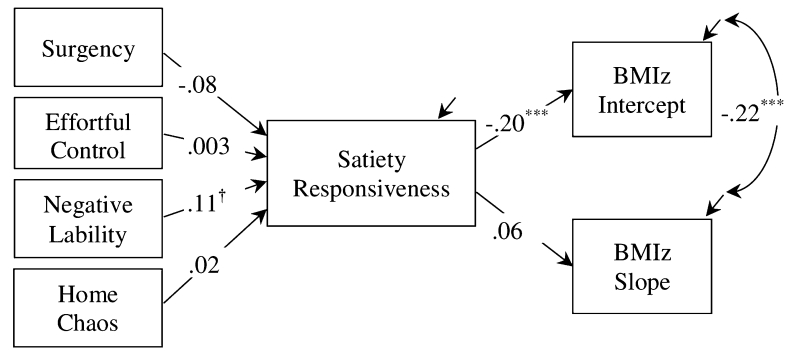

Figure 1 Path model for the links between temperament, eating behaviour and BMlz growth pattern, controlling for home chaos. Note: Four eating behaviours including (a) food responsiveness, (b) enjoyment of food, (c) emotional overeating and (d) satiety responsiveness were tested individually in each of four models. Intercorrelations between exogenous variables were estimated in each model; the double arrows and correlation estimates were not included in the figure to make the figure as parsimonious as possible. ${ }^{\dagger} P<.10$. ${ }^{\star} P<.05 .{ }^{\star \star} P<.01{ }^{\star \star \star} P<.001$. All models have good fit with model-fit statistics on the recommended range: for each model, the $\chi^{2}$-fit statistics was highly non-significant. $P$-value $>.05, \mathrm{CFI}>.9, \mathrm{SRMR}<.06$. 
Table 1 Characteristics of the sample $(N=379)$

\begin{tabular}{lcc}
\hline Demographic characteristics & Mean & SD \\
\hline Primary caregiver age (years) & 29.09 & 6.95 \\
Child age at initial assessment (years) & 4.22 & 0.53 \\
Child race and ethnicity & $N$ & $\%$ \\
White, non-Hispanic & 212 & 55.9 \\
Black, non-Hispanic & 59 & 15.6 \\
Biracial/multiracial, non-Hispanic & 63 & 16.6 \\
Hispanic, any race & 43 & 11.3 \\
Child sex, male & 189 & 49.9 \\
Primary caregiver education & $N$ & $\%$ \\
Did not complete high school & 62 & 16.4 \\
Graduated from high school or & 122 & 32.2 \\
equivalent & & \\
Attended fewer than 2 years of & 152 & 40.1 \\
college & & \\
Earned a 2-year degree & 43 & 11.3 \\
Predictors: child temperament & Mean & SD \\
dimensions* & & \\
CBQ surgency & 4.86 & 0.78 \\
CBQ effortful control & Mean & SD \\
ERC negative lability & 4.08 & 3.22 \\
Mediator: child eating behaviours* & Mean & SD \\
CEBQ food responsiveness & 2.48 & 0.89 \\
CEBQ enjoyment of food & 3.79 & 0.78 \\
CEBQ emotional overeating & 1.96 & 0.70 \\
CEBQ satiety responsiveness & 2.98 & 0.69 \\
Outcomes: child body mass index z & Mean & SD \\
score (BMlz) & & \\
Concurrent BMlz & 0.77 & 1.02 \\
Rate of change in BMlz & & 0.13 \\
Covariate* & & \\
CHAOS total score & & \\
\hline
\end{tabular}

*Higher scores represent higher levels of the corresponding variable, ranging from 1 to 7 for the CBQ surgency and effortful control scales, 1 to 4 for the ERC negative lability scale, 1 to 5 for the CEBQ scales, and 1 to 15 for the CHAOS scale. CBQ, Children's Behaviour Questionnaire; CEBQ, Children's Eating Behaviour Questionnaire; CHAOS, Confusion, Hubbub, and Order Scale; ERC, Emotion Regulation Checklist.

responsiveness did not mediate the association between surgency and the rate of increase in BMlz. The BMlz growth pattern at high vs. low levels of food responsiveness (defined as $1 \mathrm{SD}$ above and below the mean) is shown in Fig. 2a.

Enjoyment of food significantly mediated the association between surgency and BMlz. Higher surgency was associated with more enjoyment of food, $\beta=.23$. More enjoyment of food in turn was associated with higher BMlz, $\beta=.27$. The indirect effect of surgency on BMlz through enjoyment of food was significant. Enjoyment of food did not mediate the association between surgency and the rate of increase in BMlz. The BMlz growth pattern at high vs. low levels of enjoyment of food (defined as 1 SD above and below the mean) is shown in Fig. $2 b$.
Neither effortful control nor negative lability was significantly associated with eating behaviours, BMlz intercept or BMlz slope. Given these non-significant paths, there was no evidence for an indirect effect of effortful control or negative lability on BMlz intercept or slope through eating behaviours. The four mediation models were also tested in boys and girls separately and no substantial differences in the pattern of results were found between boys and girls.

\section{Discussion}

This study had three main findings. First, more surgent pre-schoolers were more responsive to food cues in the environment and enjoyed food more, each of which in turn was associated with higher BMlz. Each of these two eating behaviours fully mediated the association of surgency with BMlz. These findings suggest that associations between surgent temperament and obesity risk are operating through eating behaviour among low-income preschoolers. Obesity prevention programmes may thus increase their effectiveness by focusing on low-income young children with high surgency who are particularly at risk, and attempting to modify the food environment for these children. Specifically, our findings suggest that because surgent children particularly enjoy food and attend to food cues in the environment, reducing their exposure to the pervasive food cues in the current environment may be especially important for this subgroup.

Second, contrary to our hypothesis, greater surgency was not associated with greater increases in low-income children's BMlz from ages 4 to 6 years. Rather, children described by their caregivers at ages 3-4 years as having high surgency, food responsiveness and enjoyment of food already had a higher BMI relative to their same-age peers and that higher BMI continued to track at the higher level for the nearly 2-year follow-up period. This observation suggests that the links between a surgent temperament and these obesity-promoting eating behaviours may need to be addressed prior to age 3 years to effectively prevent unhealthy increases in BMI.

Third, neither effortful control nor negative lability was associated with eating behaviours or BMI. Our study is not the first to be unable to detect a significant association of effortful control with BMI in pre-school-aged children $(6,7)$. Links between effortful control and BMl may emerge only later in childhood when self-regulation specific to eating (e.g. self-restraint in response to palatable food) may become a more expected behaviour. Indeed, at least one study has suggested that links between self-regulatory capacity and BMI only emerge later in childhood (6). Mechanisms by which effortful control may be associated with BMI longitudinally deserve further consideration in future research. Although there has been interest in negativity, sometimes characterized as 'difficult temperament', as a predictor of obesity risk in children $(4,5)$, the literature suggesting that negative affectivity is actually associated with undereating or selective eating behaviours (19-21) has contributed to uncertainty about this association. In this study, negative lability primarily captured anger and 

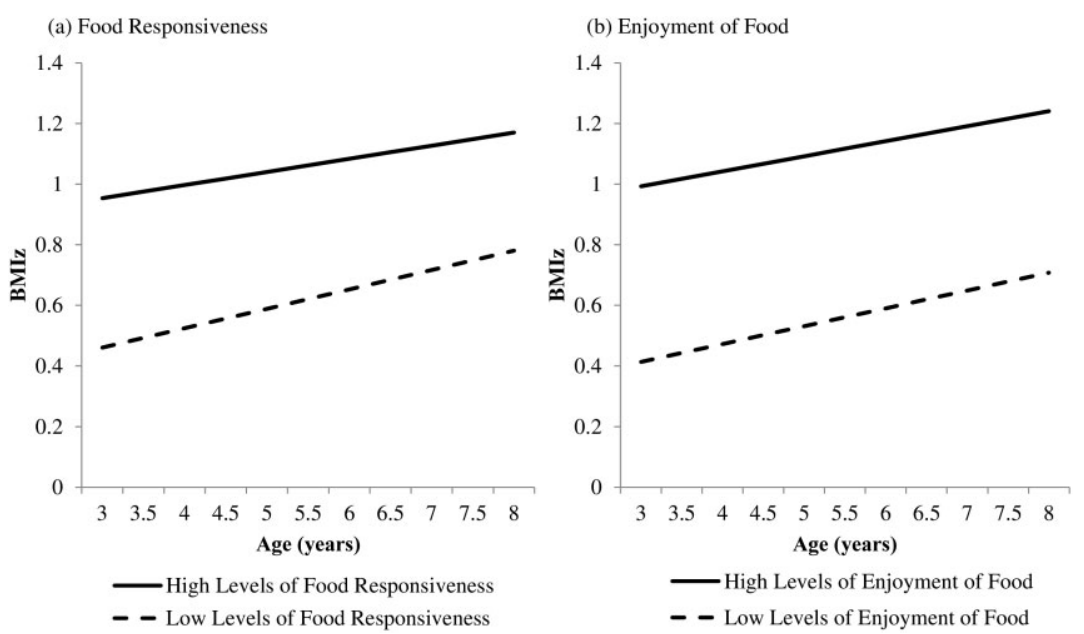

Figure 2 BMlz growth pattern at high vs. low levels of eating behaviours.

distress to limits, which might contribute to the inability to detect an association with either eating behaviour or BMI. Future work might consider measuring temperamental negativity and moderators of the association such as child age, socioeconomic status or parenting that could be masking a direct association.

Strengths of the present study include using repeated objective measures of height and weight, reliable and valid questionnaires, and HLM to capture individual $\mathrm{BMl}$ growth curves. Nevertheless, findings should be interpreted in light of the study limitations. This study focused on temperamental negative lability and did not capture all types of temperamental negativity. In addition, the results may not be generalizable to populations that are not lowincome pre-schoolers from the Midwestern United States.

In summary, this study found that low-income preschoolers with a surgent temperament are more likely to respond to food cues in the environment and to enjoy food, and these behaviours, in turn, are associated with greater adiposity by ages 3-4 years. Clinicians might consider explaining the risks of this behaviour pattern to caregivers in infancy and toddlerhood, so that caregivers can be attentive to the food environment and how they manage the child's eating behaviour.

\section{Conflict of Interest Statement}

All authors have no conflicts of interest to disclose.

\section{Acknowledgements}

All phases of this study were supported by funding from NIH RC1DK086376 (Principal Investigator: Julie Lumeng), NIDDK R21DK090718 (Principal Investigator: Julie Lumeng and Alison Miller), American Heart Association 10GRNT4460043 (Principal Investigator: Alison Miller) and NICHD R01HD061356 (Principal Investigator: Julie Lumeng). All authors affirm that the first author (Christy
Leung) wrote the first draft of the manuscript, and each author listed on the manuscript has revised and approved the submission of this version of the manuscript and takes full responsibility for the manuscript.

\section{References}

1. Ogden CL, Carroll MD, Kit BK, Flegal KM. Prevalence of childhood and adult obesity in the United States, 20112013. JAMA 2014; 311: 806-814.

2. Rothbart M, Ahadi S, Hersey K, Fisher P. Investigations of temperament at three to seven years: the Children's Behavior Questionnaire. Child Dev 2001; 72: 1394-1408. 3. Burton P, Wells JCK, Kennedy K, Nicholl R, Khahoo A, Fewtell MS. Association between infant correlates of impulsivity-surgency (extraversion)-and early infant growth. Appetite 2011; 57: 504-509.

4. Agras W, Hammer L, McNicholas F, Kraemer H. Risk factors for childhood overweight: a prospective study from birth to 9.5 years. J Pediatr 2004; 145: 20-25.

5. Graziano PA, Calkins SD, Keane SP. Toddler selfregulation skills predict risk for pediatric obesity. Int J Obes 2010; 34: 633-641.

6. Francis LA, Susman EJ. Self-regulation and rapid weight gain in children from age 3 to 12 years. Arch Pediatr Adolesc Med 2009; 163: 297-302.

7. Seeyave DM, Coleman SS, Appugliese DD, et al. Ability to delay gratification at age 4 years and risk of overweight at age 11 years. Arch Pediatr Adolesc Med 2009; 163: 303-308.

8. Faith M, Hittner J. Infant temperament and eating style predict change in standardized weight status and obesity risk at 6 years of age. Int J Obes 2010; 34: 1515-1523.

9. Pulkki-Råback L, Elovainio M, Kivimäki M, Raitakari O, Keltikangas-Järvinen L. Temperament in childhood predicts body mass in adulthood: the cardiovascular risk in young Finns study. Health Psychol 2005; 24: 307-315.

10. Jahnke DL, Warschburger PA. Familial transmission of eating behaviors in preschool-aged children. Obesity 2008; 16: 1821-1825. 
11. Braet C, Claus L, Goossens L, Moens E, van Vlierberghe L, Soetens B. Differences in eating style between overweight and normal-weight youngsters. J Health Psychol 2008; 13: 733-743.

12. Spence JC, Carson V, Casey L, Boule N. Examining behavioral susceptibility to obesity among Canadian preschool children: the role of eating behaviors. Int J Pediatr Obes 2011; 6: e501-e507.

13. Wardle J, Guthrie C, Sanderson S, Rapoport L. Development of the children's eating behaviour questionnaire. J Child Psychol Psychiatry 2001; 42: 963-970.

14. Anzman-Frasca SS, Stifter CA, Birch LL. Temperament and childhood obesity risk: a review of the literature. J Dev Behav Pediatr 2012; 33: 732-745.

15. Jasinska AJ, Yasuda M, Burant CF, et al. Impulsivity and inhibitory control deficits are associated with unhealthy eating in young adults. Appetite 2012; 59: 738-747.

16. Tan CC, Holub SC. Children's self-regulation in eating. Associations with inhibitory control and parents' feeding behavior. J Pediatr Psychol 2011; 36: 340-345.

17. Pieper JR, Laugero KD. Preschool children with lower executive function may be more vulnerable to emotionalbased eating in the absence of hunger. Appetite 2013; 62: 103-109.

18. Bergmeier $H$, Skouteris $H$, Horwood S, Hooley M, Richardson B. Child temperament and maternal predictors of preschool children's eating and body mass index. A prospective study. Appetite 2014; 74: 125-132.

19. Haycraft E, Farrow C, Meyer C, Powell F, Blissett J. Relationships between temperament and eating behaviours in young children. Appetite 2011; 56: 689692.

20. Leung CYY, Lumeng JC, Kaciroti NA, Chen Y-P, Rosenblum K, Miller AL. Surgency and negative affectivity, but not effortful control, predict obesogenic eating behaviors among low-income preschoolers. Appetite 2014; 78: 139-146.

21. Taylor RW, Grant AM, Goulding A, Williams S. Early adiposity rebound: a review of papers linking this to subsequent obesity in children and adults. Curr Opin Clin Nutr Metab Care 2005; 8: 607-611.

22. Hughes A, Sherriff A, Ness A, Reilly J. Timing of adiposity rebound and adiposity in adolescence. Pediatrics 2014; 134: e1354-e1361.

23. Lo J, Maring B, Greenspan L, et al. Prevalence of obesity and extreme obesity in children aged 3-5 years. Pediatr Obes 2014; 9: 167-175.

24. Anderson SE, Whitaker RC. Household routines and obesity in US preschool-aged children. Pediatrics 2010; 125: 420-428.

25. Shields A, Cicchetti D. Reactive aggression among maltreated children: the contributions of attention and emotion dysregulation. J Clin Child Psychol 1998; 27: 381-395.

26. Kuczmarski RJ, Ogden CL, Grummer-Strawn LM, et al. CDC growth charts: United States. Adv Data 2000; 314: 1-27.

27. Matheny A, Wachs T, Ludwig J, Phillips K. Bringing order out of chaos: psychometric characteristics of the Confusion, Hubbub, and Order Scale. J Appl Dev Psychol 1995; 16: 429-444.

28. Hruschka D, Kohrt B, Worthman C. Estimating between- and within-individual variation in cortisol levels using multilevel models. Psychoneuroendocrinology 2005; 30: 698-714.

29. Hu L, Bentler P. Cutoff criteria for fit indexes in covariance structure analysis: conventional criteria versus new alternatives. Struct Equ Modeling 1999; 6: 1-55. 